Magna Scientia Advanced Research and Reviews

eISSN: 2582-9394

Cross Ref DOI: 10.30574/msarr

Journal homepage: https://magnascientiapub.com/journals/msarr/

(RESEARCh ARTiCle)

\title{
Oral hygiene practice, dental profile and dental service utilization of chronic kidney disease patients
}

\author{
Soroye Modupeoluwa Omotunde ${ }^{1, *}$ and Onigbinde Olubunmi Omotunde ${ }^{2}$ \\ ${ }^{1}$ Department of Preventive Dentistry, Faculty of Dentistry, University of Port Harcourt, Port Harcourt, Rivers State, Nigeria. \\ 2 Department of Preventive Dentistry, Lagos State University College of Medicine, Lagos, Lagos State, Nigeria.
}

Magna Scientia Advanced Research and Reviews, 2022, 04(01), 068-077

Publication history: Received on 17 January 2022; revised on 22 February 2022; accepted on 24 February 2022

Article DOI: https://doi.org/10.30574/msarr.2022.4.1.0028

\begin{abstract}
Background: Research has shown that as high as $90 \%$ of patients with renal disease show oral symptoms. Literature supports a bidirectional relation between CKD and periodontal disease.

Methods: A cross-sectional survey among patients diagnosed with CKD who attended the renal outpatient clinic of a teaching hospital in south-south, Nigeria. Self-administered questionnaire was used to collect participant's demographics and dental profile. Oral hygiene gingival and dental status were assessed with Simplified oral hygiene index (OHI-S), gingival index and DMFT. Data analysis was done with IBM Statistical Package for Social Science (SPSS) for windows version 21.0 and results presented as tables.

Results: One hundred and seven consenting participants were recruited for the study. Age ranged between 18 and 86 years with mean age of $52.93 \pm 5.74$ years. Median year of diagnosis was 4 years. Hypertension was the major cause of CKD in three-quarters of participant, two-third were in the 4th stage of disease, $95.3 \%$ used toothbrush/paste to clean their teeth, $14 \%$ brushed twice daily and $18.7 \%$ reported interdental cleaning. Only $9.3 \%$ of participants regularly visit the dentist and reasons for non-regular visit varied. Four-fifth of participants had poor oral hygiene. Mean OHI-S was $4.52 \pm 1.46$. Four-fifth of participants reported gingival bleeding while brushing. $87.9 \%$ had gingival index of 2 and 3 . A quarter had xerostomia. Mean DMFT was 0.39 \pm 0.87 .
\end{abstract}

Conclusion: The oral health status of participants was poor. Oral health care should be incorporated into the management of patients with chronic kidney disease as this will help improve their quality of life.

Keywords: CKD; Dental visit; Dental profile; Gingival status; Oral hygiene status

\section{Introduction}

Oral health has been defined as the ability to speak, smile, smell, taste, touch, chew, swallow and convey a range of emotions through facial expressions with confidence and without pain, discomfort and disease of the craniofacial complex [1]. Association has been reported between poor oral hygiene and chronic renal disease (CKD) [2].

Chronic renal disease (CKD) is defined as kidney damage or glomerular filtration rate of $<60 \mathrm{Ml} / \mathrm{min} / 1.73 \mathrm{~m}^{2}$ for $\geq 3$ months [2]. Kidney damage is the structural or functional abnormalities of the kidney without decreased GFR initially but which over time can lead to decreased GFR [2,3]. CKD has been associated with several oral changes in ninety percent of those diagnosed [3].

\footnotetext{
${ }^{*}$ Corresponding author: Soroye Modupeoluwa Omotunde

Department of Preventive Dentistry, Faculty of Dentistry, University of Port Harcourt, Port Harcourt, Rivers State, Nigeria.

Copyright (C) 2022 Author(s) retain the copyright of this article. This article is published under the terms of the Creative Commons Attribution Liscense 4.0.
} 
These oral changes are periodontal disease, dental caries, gingival enlargement as a side effect of some renal drugs and changes in salivary composition and rate leading to xerostomia [3-5]. The most common oral finding reported was pallor of the oral mucosa [6].

CKD is a non-communicable disease usually caused by diabetes and hypertension [7]. it is defined by the National Kidney Foundation (NKF) as kidney damage occurring for three or more months that is associated with structural or functional abnormalities with or without decreased glomerular filtration rate (GFR) [7-10].

CKD is classified into acute, subacute, and chronic renal failure based on onset and the possibility for recovery of the structural lesion. Although acute renal failure is reversible in most cases, chronic renal failure (CRF) presents as a progressive disease that ends in terminal renal failure (TRF) even if the cause of the initial nephropathy disappears [11, 12].

The global prevalence of CKD in 2017 was $9.1 \%$ accounting for roughly 700 million cases worldwide and was responsible for 1.2 million deaths [13]. It was the fifth cause of death in Latin America. ${ }^{12}$ CKD is a growing challenge in low- and middle- income countries in Sub-Saharan African with 16\% recorded as pooled prevalence [14, 15]. In Nigeria, the prevalence of CKD is $1.8 \%$ to $43.5 \%$ depending on the studied population [16].

Oral bacteria that are present in dental plaque can disseminate through circulating blood during swallowing and induce systemic changes in distant tissues in the body [17]. Between $10^{6}-10^{8}$ of Porphyromonas gingivalis and Tannerella forsythia have been reportedly found per $\mathrm{mL}$ of subgingival and salivary samples in periodontitis patients and some of these can be swallowed daily [18]. Oral bacteria can enter the circulation and cause bacteremia by actively crossing the periodontal epithelium $[18,19]$. The direct or indirect effects of circulating bacteria, inflammatory mediators and immune complexes from infected or inflamed periodontal tissues on other body sites are some of the main mechanisms that contribute to systemic inflammation [19]. There is strong evidence that the pathogenic microbiota and chronic inflammation established in poor oral hygiene contribute to the progression of CKD [20,21].

Dental caries is a biofilm-mediated disease with multiple contributing factors that drives net localized demineralization of the teeth [22]. Dental caries is prevalent, and if untreated it has a direct effect on both the oral and systemic health $[20,23]$. Though, dental caries and periodontitis- a sequalae of untreated gingivitis due to poor oral hygiene, are both biofilm-mediated diseases, the pathogenesis of dental caries is complex and multifactorial and differs from periodontal disease [22]. The ability of oral microbiome to spread into systemic circulation from dental caries is plausible and would parallel mechanisms that already have been studied for periodontal disease [24].

This study assessed the oral health of chronic kidney patients in a tertiary hospital in Nigeria.

\section{Material and methods}

A descriptive cross-sectional study conducted between June and September 2021 at the renal outpatient clinic of University of Port Harcourt Teaching Hospital (UPTH)) in South-South, Nigeria. Ethical approval was obtained from the ethics committee of the hospital.

The inclusion criteria were patients 18 years and above diagnosed with chronic kidney disease for at least 1 year before the study, gave consent to be part of the study and are permanent residents in the study location. Those who smoked or consumed alcohol were excluded from the study. One hundred and seven subjects who gave consent were recruited.

Self-administered questionnaires were used to collect data on demographics, CKD and dental profiles. Oral cleanliness was assessed using Simplified Oral hygiene index by Greene and Vermillion [25, 26] and gingival status assessed with gingival index by Loe and Silness [27]. Classification of CKD was done based on National Kidney Foundation (NKF) 2019 (Kidney Disease Outcomes Quality Initiative) KDOQI guidelines [28].

The OHI-S is a composite index that scores debris and calculus deposition on selected teeth. It was developed by Greene and Vermillion in 1964. It is expressed as the sum of the mean debris index (DI-S) and calculus index (CI-S) of the examined teeth. The OHI-S is interpreted as follows: Score 1 (good oral hygiene) $=0.0-1.2$, Score 2 (fair oral hygiene) $=1.3-3.0$, Score 3 (poor oral hygiene) $=3.1-6.0$.

Gingival index (GI) may be used for the assessment of prevalence and severity of gingivitis in populations, groups and individuals. A score from 0-3 with $0=$ No inflammation; $1=$ mild inflammation; $2=$ moderate inflammation and 3 signifies severe inflammation. 
Decayed, missing and filled teeth (DMFT) index was used to assess dental status [29]. DMFT is the sum of the number of Decayed, missing due to caries, and filled teeth in the permanent teeth. The mean number of DMFT is the sum of individual DMFT values divided by the sum of the population

The KDOQI guidelines categorized CKD into 5 stages. Stage 1 is Normal or high GFR (GFR > $90 \mathrm{~mL} / \mathrm{min}$ ); Stage 2 = Mild CKD (GFR = 60-89 mL $/ \mathrm{min})$; Stage 3A = Moderate CKD (GFR = 45-59 mL $/ \mathrm{min})$; Stage 3B = Moderate CKD (GFR = 30 -44 $\mathrm{mL} / \mathrm{min})$; Stage 4 = Severe CKD (GFR = 15-29 mL/min); Stage $5=$ End Stage CKD $(\mathrm{GFR}<15 \mathrm{~mL} / \mathrm{min}$.

Data was analyzed using the Statistical Package for Social Sciences version 20.0 (IBM SPSS Statistics Armonk New York. The results were presented as tables.

\section{Results}

Table 1 shows participants' demographics. Age ranged between18 and 86 years with mean age of $52.93 \pm 5.74$ years. There was a male predominance with M: F of 1.43: 1 and median year of diagnosis was 4 years. Hypertension was the cause of CKD in three-quarters of the participants. Two-third were in the 4 th stage of disease.

Table 1 Participants' characteristics

\begin{tabular}{|c|c|c|}
\hline Variables & Frequency & Percentage \\
\hline \multicolumn{3}{|l|}{ Sex } \\
\hline Male & 63 & 58.9 \\
\hline Female & 44 & 41.1 \\
\hline \multicolumn{3}{|c|}{ Age group (years) } \\
\hline $10-21$ & 2 & 1,9 \\
\hline $21-30$ & 8 & 7.5 \\
\hline $31-40$ & 16 & 15.0 \\
\hline $41-50$ & 23 & 21.5 \\
\hline $51-60$ & 20 & 18.7 \\
\hline $61-70$ & 25 & 23.4 \\
\hline$>70$ & 13 & 12.0 \\
\hline \multicolumn{3}{|c|}{ Mean age $=52.93 \pm 5.74$ years } \\
\hline \multicolumn{3}{|l|}{ Ethnicity } \\
\hline Hausa & 1 & 0.9 \\
\hline Igbo & 12 & 11.2 \\
\hline Yoruba & 5 & 4.7 \\
\hline South-South & 89 & 83.2 \\
\hline \multicolumn{3}{|l|}{ Education } \\
\hline No formal & 13 & 12.1 \\
\hline Primary & 16 & 15.0 \\
\hline Secondary & 36 & 33.6 \\
\hline Tertiary & 42 & 39.3 \\
\hline \multicolumn{3}{|l|}{ Occupation } \\
\hline Students & 3 & 2.8 \\
\hline Self-employed & 62 & 57.9 \\
\hline Civil servants & 27 & 25.3 \\
\hline Professionals & 15 & 14.0 \\
\hline
\end{tabular}




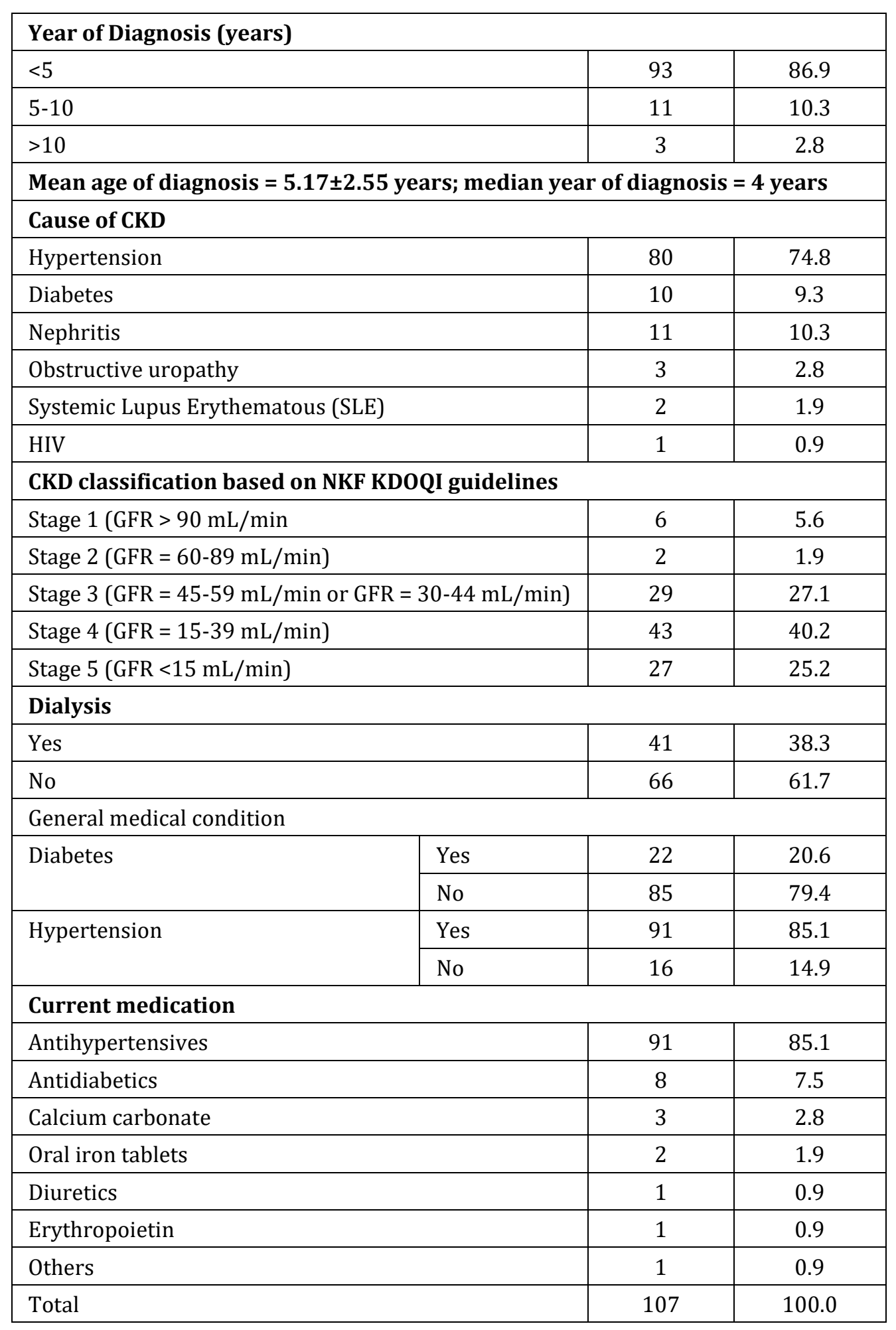

Majority of participants used toothbrush and paste to clean their teeth with only $14 \%$ brushing twice daily. $57 \%$ used medium bristled toothbrush. $18.7 \%$ of participants claimed to clean interdentally. Table 2 .

As regards dental service utilization, only $9.3 \%$ of participants regularly visit the dentist. Reasons for non-regular visit varied. Table 3 .

Participants dental profile showed that four-fifth of participants had poor oral hygiene. Mean OHI-S was $4.52 \pm 1.46$. Four-fifth of participants reported gingival bleeding while brushing. $87.9 \%$ had gingival index of 2 and 3 . A quarter had 
xerostomia. Mean Decayed, Missing, and Filled Teeth (DMFT) was $0.39 \pm 0.87$. The mean differences between the different components of teeth including DMFT were smaller Table 4.

Table 2 Participants oral hygiene practice

\begin{tabular}{|c|c|c|}
\hline Variables & Frequency & Percentage \\
\hline \multicolumn{3}{|l|}{ Cleaning items } \\
\hline Toothbrush/paste & 102 & 95.3 \\
\hline Toothpaste/chewing stick & 2 & 1.9 \\
\hline Chewing stick & 3 & 2.8 \\
\hline \multicolumn{3}{|l|}{ Frequency of cleaning } \\
\hline Once daily & 91 & 85.0 \\
\hline Twice daily & 15 & 14.0 \\
\hline After every meal & 1 & 1.0 \\
\hline \multicolumn{3}{|l|}{ Toothbrush bristled } \\
\hline Soft & 23 & 21.5 \\
\hline Medium & 61 & 57.0 \\
\hline Hard & 23 & 21.5 \\
\hline \multicolumn{3}{|l|}{ Interdental cleaning } \\
\hline Yes & 20 & 18.7 \\
\hline No & 87 & 81.3 \\
\hline \multicolumn{3}{|c|}{ Interdental cleaning materials } \\
\hline Dental floss & 6 & 30.0 \\
\hline Interdental brush & 1 & 5.0 \\
\hline Toothpick & 13 & 65.0 \\
\hline \multicolumn{3}{|l|}{ Interdental cleaning period } \\
\hline After brushing & 2 & 10.0 \\
\hline After eating & 15 & 75.0 \\
\hline Anytime & 3 & 15.0 \\
\hline Total & 107 & 100.0 \\
\hline
\end{tabular}

Table 3 Participants' dental service utilization

\begin{tabular}{|l|c|c|}
\hline Variables & Frequency & Percentage \\
\hline Regular dental visit & 10 & 9.3 \\
\hline Yes & 97 & 90.7 \\
\hline No & 37 & 34.6 \\
\hline Past dental visit & 70 & 65.4 \\
\hline Yes & 107 & 100.0 \\
\hline No & \multicolumn{2}{|l}{} \\
\hline Total & 4 & 10.8 \\
\hline Reasons for past dental visit & 17 & 46.0 \\
\hline Routine check-up &
\end{tabular}




\begin{tabular}{|l|c|c|}
\hline Extraction & 16 & 43.2 \\
\hline Total & 37 & 100.0 \\
\hline \multicolumn{2}{|l|}{ Reasons for non-utilization } \\
\hline No time & 42 & 43.3 \\
\hline No dental problem & 18 & 18.6 \\
\hline High cost of treatment & 24 & 24.7 \\
\hline Far distance & 13 & 13.4 \\
\hline Total & 97 & 100.0 \\
\hline
\end{tabular}

Table 4 Participants dental profile

\begin{tabular}{|c|c|c|}
\hline Variables & Frequency & Percentage \\
\hline \multicolumn{3}{|c|}{ Simplified oral hygiene index (OHI-S) } \\
\hline Fair $(1.3-3.0)$ & 20 & 18.7 \\
\hline Poor $(3.1-6.0)$ & 87 & 81.3 \\
\hline \multicolumn{3}{|c|}{ Mean OHI-S = $4.52 \pm 1.46$} \\
\hline \multicolumn{3}{|c|}{ Mean plaque score $=2.31 \pm 0.75$} \\
\hline \multicolumn{3}{|c|}{ Self-reported gingival bleeding } \\
\hline Yes & 84 & 78.5 \\
\hline No & 23 & 21.5 \\
\hline \multicolumn{3}{|c|}{ Self-reported severity of gingival bleeding } \\
\hline Mild & 11 & 10.2 \\
\hline Moderate & 48 & 44.9 \\
\hline Severe & 48 & 44.9 \\
\hline \multicolumn{3}{|l|}{ Gingival index } \\
\hline 1 & 13 & 12.1 \\
\hline 2 & 45 & 42.1 \\
\hline 3 & 49 & 45.8 \\
\hline \multicolumn{3}{|c|}{ Gingival recession } \\
\hline Yes & 59 & 55.1 \\
\hline No & 48 & 44.9 \\
\hline \multicolumn{3}{|c|}{ Periodontal pocket } \\
\hline Yes & 10 & 9.3 \\
\hline No & 97 & 90.7 \\
\hline \multicolumn{3}{|l|}{ Periodontitis } \\
\hline Yes & 69 & 64.5 \\
\hline No & 38 & 35.5 \\
\hline \multicolumn{3}{|l|}{ Halitosis } \\
\hline Yes & 54 & 50.5 \\
\hline No & 53 & 49.5 \\
\hline \multicolumn{3}{|l|}{ Xerostomia } \\
\hline Yes & 26 & 24.3 \\
\hline No & 81 & 75.7 \\
\hline
\end{tabular}




\begin{tabular}{|l|c|c|}
\hline \multicolumn{3}{|l|}{ Change in taste } \\
\hline Yes & 51 & 47.7 \\
\hline No & 56 & 52.3 \\
\hline Total & 107 & 100.0 \\
\hline Teeth variables & Mean $(95 \% \mathrm{CI})(\mathrm{N}=107)$ \\
\hline Teeth present & $31.31(30.93,31.70) \dagger$ \\
\hline Missing teeth & $0.59(0.26,0.94) \dagger$ \\
\hline Carious teeth & $0.21(0.04,0.37) \dagger$ \\
\hline Filled teeth & $0.09(0.04,0.23) \dagger$ \\
\hline DMFT & $0.39(0.23,0.59) \dagger$ \\
\hline \multicolumn{2}{|c|}{$\dagger$ Denotes non-overlapping $95 \%$ confidence intervals } \\
\hline
\end{tabular}

\section{Discussion}

With the increase in the prevalence of CKD in Nigeria, there is the need to promote oral health among the populace as those diagnosed with the condition require holistic care. Ninety percent of those diagnosed have been reported to have associated oral symptoms [3]. This study evaluated the oral health of Nigerians diagnosed with chronic kidney disease.

Participants' age ranged from 18 years to 86 years with mean age of $52.93 \pm 5.74$ years. This is comparable to a study done among aboriginal Australians that reported a mean age of 48.11 years [7]. This study reported a male predominance like the Australian study and the one among CKD patients in Government hospitals in India [7, 11]. Half of the participants in this study were in the 31-60 years age group. The prevalence of CKD increased with age in this study group and compares with the Indian study [11]. 25\% of participants older than 60 years had estimated GFR of less than $60 \mathrm{ml} / \mathrm{min} / 1.73 \mathrm{~m}^{2}$. The Indian study reported that $17 \%$ of participants older than 60 years had GFR less than $60 \mathrm{ml} / \mathrm{min}[11]$.

Though, the aetiology of kidney disease is multifactorial, hypertension and diabetes were the most common causes worldwide [30]. In the United State of America, hypertension and diabetes were reported as the major cause of 3 out of 4 new cases [31]. In developing countries, glomerulonephritis and interstitial nephritis were reported as the commonest causes [32]. In this study, the two major causes in the participants were hypertension (74.8\%) and nephritis (10.3\%). Other studies done in Nigeria reported high prevalence of hypertension among their study participants [16, 33-35].

CKD patients have been reported to present with xerostomia (dry mouth), candidiasis, alteration in taste, periodontitis, dental caries and tooth loss [6,36]. Taste alteration is commonly reported among CKD patients although the underlying mechanism is not well understood. The change in taste among the participants may be from the effect of ureamic toxins on the central nervous system (CNS) and the peripheral nervous system (the taste receptors) [37]. The occurrence of dry mouth may be as a result of fluid restriction, electrolyte imbalance and use of drugs that have xerostomia as side effects. Halitosis has been attributed to poor oral hygiene and uremic smell [36].

The participants that presented with altered taste, xerostomia and halitosis in this study were $50.5 \%, 47.7 \%$ and $24.3 \%$ respectively. The study done among CKD patients in a teaching hospital in Ile-Ife Nigeria reported that $26 \%, 22.2 \%$ and $12 \%$ of their participants had alteration in taste, xerostomia and halitosis respectively [8]. Other studies reported prevalence of xerostomia of $32.9 \%$ and $48.2 \%$ among their participants [38, 39]. Another study done among CKD patients in a teaching hospital in Lagos, Nigeria reported a prevalence of $36.9 \%$ of altered taste among participants. ${ }^{39}$ Similar to the Lagos study that reported prevalence of candidiasis among participants as only $1.5 \%$, this study reported a $1.9 \%$ prevalence [39].

Gingival bleeding, the first sign of gum inflammation, is seen commonly in poor oral hygiene. This will lead to periodontal disease if the gingival inflammation is left untreated. About two-fifth of participants in this study reported gingival bleeding. Clinical examination showed that $100 \%$ of participants had gingivitis and $64.5 \%$ had periodontitis. $9.3 \%$ and $55.1 \%$ of participants had periodontal pocket and gingival recession respectively. The Ile-Ife study reported gingival/periodontal inflammation among $97.7 \%$ of participants [8].

This study did not report gingival hyperplasia among participants despite that majority (81.3\%) of participants had poor oral hygiene similar to the Ile-Ife study [8]. Gingival swelling secondary to use of nifedipine and cyclosporine have 
been reported among CKD patients [35]. However, hypertension is treated in most Nigerian teaching hospitals with amlodipine [39]. Also, most patients with CKD in Nigeria usually cannot afford renal transplant and would not need to be placed on immunosuppressants [35, 40-42].

Less than $10 \%$ of participants visit the dentists regularly despite the associated oral conditions secondary to CKD and $81.3 \%$ had poor oral hygiene. CKD patients have been reported to have reduced dental visits which further worsen their oral conditions [43]. This may be as a result of the high financial and emotional burdens CKD places on those diagnosed and also because most Nigerians don't present early to the health facilities when sick. They usually wait until they have tried various forms of alternative medicine (spiritual and traditional/native healers) [44-46]. This attitude may probably be as a result of ignorance and the poor accessibility and lack of affordable oral health care services $[8,46]$.

Tooth loss is the sequalae to untreated periodontal disease. $52 \%$ of participants had periodontitis. This is not surprising as four-fifth had poor oral hygiene. The values of the mean differences between the different components of teeth including DMFT at 95\% confidence interval were smaller compared to that reported by the Australian study [5]. This may be because most of the participants had full complement of teeth.

\section{Conclusion}

The oral hygiene and dental status of the participants as well as the use of dental services was poor.

\section{Compliance with ethical standards}

\section{Acknowledgments}

All individuals who participated in the study.

\section{Disclosure of conflict of interest}

The authors declare no conflict.

\section{Statement of informed consent}

Informed consent was obtained from all individual participants included in the study.

\section{References}

[1] Glick M, Williams DM, Kleinman DV, Vujicic M, Watt RG, Weyant RJ. A new definition for oral health developed by the FDI World Dental Federation opens the door to a universal definition of oral health. Br Dent J. 2016; 221: 792-793.

[2] Jha V, Garcia-Garcia G, Iseki K, Li Z, Naicker S, Plattner B, Saran R, et al. chronic kidney disease: global dimension and perspectives. Lancet. 2013; 382(9888): 260-272.

[3] Honarmand M, Farhad-Mollashahi L, Nakhaee A, Sargolzaie F. Oral manifestation and salivary changes in renal patients undergoing hemodialysis. J Clin Exp Dent. 2017; 9(2): e207-e210.

[4] Anuradha BR, Katta S, Kode VS, Praveena C, Sathe N, Sandeep N, et al. Oral and salivary changes in patients with chronic kidney disease: A clinical and biochemical study. J Indian Soc Periodontol. 2015; 19(3): 297-301.

[5] Kapellas K, Hughes JT, Cass A, Maple-Brown LJ, Skilton MR, Harris D, et al. Oral health of aboriginal people with kidney disease living in Central Australia. BMC Oral Health. 2021; 21(1): 50.

[6] Saini R, Sugandha, Saini S. The importance of oral health in kidney diseases. Saudi J Kidney Dis Transpl. 2010; 21: 1151-1152.

[7] Souza CM, Braosi AP, Luczyszyn SM, Casagrande RW, Pecooits-Filho R, Riella MC, et al. Oral health in Brazilian patients with chronic renal disease. Revista medica de Chile. 2008; 136(6): 741-746.

[8] Oyetola EO, Owotade FJ, Agbelusi GA, Fatusi OA, Sanusi AA. Oral findings in chronic kidney disease: implications for management in developing countries. BMC Oral Health. 2015; 15: 24.

[9] Levey A, Eckkardt K, Tsukamoto Y, Levin A, Coresh J, Rossert J, et al. Definition and classification of chronic kidney disease; a position statement from kidney disease improving global outcome. Kidney Int. 2005; 67: 2089-20100. 
[10] Levey A, Coresh J, Balk E, Kausz A, Levin A, Steffes M, et al. National foundation practice guidelines for kidney disease, evaluation, classification and stratification. Classification and Stratification Ann. Intern. Med. 2003; 139: 137-147.

[11] Gautam NR, Gautam NS, Rao TH, Koganti R, Agarwal R, Alamanda M. Effect of end-stage renal disease on oral health in patients undergoing renal dialysis: A cross-sectional study. J Int Soc Prev Community Dent. 2014; 4(3): 164-169.

[12] Sobrado Marinho JS, Tomás Carmona I, Loureiro A, Limeres Posse J, García Caballero L, Diz Dios P. Oral health status in patients with moderate-severe and terminal renal failure. Med Oral Patol Oral Cir Bucal. 2007; 12: E305310.

[13] Cousin Sobrinho EL, Duncan BB, Schmidt MI. GBD Chronic Kidney Disease Collaboration. Global, regional, and national burden of chronic kidney disease, 1990-2017: a systematic analysis for the Global Burden of Disease Study 2017. The Lancet. 2020; 395(10225): 709-733.

[14] Stanifer JW, Jing B, Tolan S, Helmke N, Mukerjee R, Naicker S, et al. The epidemiology of chronic kidney disease in sub-Saharan Africa: a systematic review and meta-analysis. Lancet Glob Health. 2014; 2(3): e174-e81.

[15] Abd-ElHafeez S, Bolignano D, D’Arrigo G, Dounousi E, Tripepi G, Zoccali C. Prevalence and burden of chronic kidney disease among the general population and high-risk groups in Africa: a systematic review. BMJ Open. 2018; 8(1): e015069.

[16] Olanrewaju TO, Aderibigbe A, Popoola AA, Braimoh KT, Buhari O, Adedoyin OT, et al. Prevalence of chronic kidney disease and risk factors in North-Central Nigeria: a population-based survey. BMC Nephrol. 2020; 21 : 467.

[17] Lourenso TGB, Spencer SJ, Alm EJ, Colombo APV. Defining the gut microbiota in individuals with periodontal diseases: an exploratory study. J. Oral Microbiol. 2018; 10: 1487741.

[18] von Troil-Lindén B, Torkko H, Alaluusua S, Jousimies-Somer H, Asikainen S. Salivary levels of suspected periodontal pathogens in relation to periodontal status and treatment. J. Dent. Res. 2016; 74: 1789-1795.

[19] Reyes L, Herrera D, Kozarov E, Roldan S, Progulske-Fox A. Periodontal bacterial invasion and infection: contribution to atherosclerotic pathology. J. Clin. Periodontol. 2013; 40(14): S30-S50.

[20] Li L, Zhang YL, Liu XY, Meng X, Zhao RQ, Ou LL et al. Periodontitis Exacerbates and Promotes the Progression of Chronic Kidney Disease Through Oral Flora, Cytokines, and Oxidative Stress. Front Microbiol. 2021; 12 : 656372.

[21] Shultis WA, Weil EJ, Looker HC, Curtis JM, Shlossman M, Genco RJ, et al. Effect of periodontitis on overt nephropathy and end-stage renal disease in type 2 diabetes. Diabetes Care. 2007; 30: 306-311.

[22] Pitts NB, Zero DT, Marsh PD, Ekstrand K, Weintraub JA, Ramos-Gomez F, et al Dental Caries. 2017; 3(1): 1-16.

[23] Sabharwal A, Stellrecht E, Scannapieco FA. Associations between dental caries and systemic diseases: a scoping review. BMC Oral Health. 2021; 21(1): 472.

[24] Scannapieco FA. The oral microbiome: its role in health and in oral and systemic infections. Clin Microbiol Newslett. 2013; 35(20): 163-169.

[25] Green JC, Vermillon JR. The simplified oral hygiene index. JADA. 1964; 68: 7-13.

[26] Shadlinskaya RV. Evaluation of oral hygiene and dental caries status in patients with beta thalassemia. Мир медицины и биологии. 2020; 16(1): 71.

[27] Aspalli S, Shetty VS, Devarathnamma MV, Nagappa G, Archana D, Parab P. Evaluation of antiplaque and antigingivitis effect of herbal mouthwash in treatment of plaque induced gingivitis: A randomized, clinical trial." Journal of Indian Society of Periodontology. 2014; 18(1): 48.

[28] Kramer HJ, Townsend RR, Griffin K, Flynn JT, Weiner DE, Rocco MV, et al. KDOQI US Commentary on the 2017 ACC/AHA Hypertension Guideline. Am J Kidney Dis. 2019; 73(4): 437-458.

[29] Menezes CR, Pereira AL, Ribeiro CC, Chaves CO, Guerra RN, Thomaz ÉB et al. Is there association between chronic kidney disease and dental caries? A case-controlled study. Med Oral Patol Oral Cir Bucal. 2019; 24(2): e211-e216.

[30] Levey AS, Atkins R, Coresh J, Cohen EP, Collins AJ, Eckardt KU, et al. chronic kidney disease as a global public health problem: approaches and initiatives - a position statement from Kidney Disease Improving Global Outcomes. Kidney Int. 2007; 72(3): 247-259. 
[31] Bowe B, Xie Y, Li T, Mokdad AH, Xian H, Yan Y, et al. Changes in the US Burden of Chronic Kidney Disease from 2002 to 2016: An Analysis of the Global Burden of Disease Study. JAMA Netw Open. 2018; 1(7): e184412.

[32] Chukwuonye II, Ogah OS, Anyabolu EN, Ohagwu KA, Nwabuko OC, Onwuchekwa U. Prevalence of chronic kidney disease in Nigeria: systematic review of population-based studies. Int J Nephrol Renovasc Dis. 22 May 2018; 11: 165-172.

[33] Adeloye D, Basquill C, Aderemi AV, Thompson JY, Obi FA. An estimate of the prevalence of hypertension in Nigeria: a systematic review and meta-analysis. J Hypertens. 2015; 33(2): 230-242.

[34] Akinlua JT, Meakin R, Umar AM, Freemantle N. Current prevalence pattern of hypertension in Nigeria: a systematic review. PLoS One. 2015; 10(10): e0140021.

[35] Proctor R, Kumar N, Stein A, Moles D, Porter S. Oral and dental aspect of chronic renal failure. J Dent Res. 2005; 84:199-208.

[36] Liabeuf S, Pepin M, Franssen CFM, Viggiano D, Carriazo S, Gansevoort RT, et al. chronic kidney disease and neurological disorders: are uraemic toxins the missing piece of the puzzle? Nephrol Dial Transplant. 2021; 28: 37(2): ii33-ii44.

[37] Hajheydari Z, Makhlough A. Cutaneous and mucosa manifestations in patients on maintenance hemodialysis. A study of 101 patients in Sari. Iran J Kidney Dis. 2008; 2: 86-90.

[38] Kho H, Lee S, Chung S, Kim Y. Oral manifestations and salivary flow rate, PH, and buffer capacity in patients with end-stage renal disease undergoing haemodialysis. Oral Surg Oral Med Oral Pathol. 1999; 88: 316-319.

[39] Soroye MO, Sorunke M. Gingival Overgrowth and associated factors in a population of Nigerian hypertensives. World Journal of Advanced Research and Reviews. 2021; 12(03): 164-174.

[40] Soroye MO, Ayanbadejo PA. Oral conditions, periodontal status and periodontal treatment need of chronic kidney disease patient. Journal of Oral Research and Review. 2016; 8(2): 53-58.

[41] Patil S, Khandelwal S, Doni B, Rahman F, Kaswan S. Oral manifestations in chronic renal failure patients attending two hospitals in North Karnataka, India. OHDM. 2012; 11: 100-106.

[42] Al-Mohaya M, Darwazeh A, Bin-Salih S, Al-Khudair W. Oral lesions in Saudi Renal transplant patients. Saudi J Kidney Dis Transpl. 2009; 20: 20-29.

[43] Xie T, Yang Z, Dai G, Yan K, Tian Y, Zhao D, et al. Evaluation of the oral health status in Chinese hemodialysis patients. Hemodial Int. 2014; 18: 668-73.

[44] Ulasi I, Chinwuba K. The enormity of chronic renal disease in Nigeria. The situation in a teaching Hospital in South-East Nigeria. Journal of Tropical Medicine volume. 2010; Article ID 501957, 6.

[45] Arogundade F, Sanusi A, Hassan M, Akinsola A. The pattern, clinical characteristics and outcome of ESRD in IleIfe, Nigeria: Is there a change in trend? African Health Sciences. 2011; 11: 594-601.

[46] Alebiosu C, Ayodele O, Abbas A, Olutoyin A. Chronic renal failure at the Olabisi Onabanjo University Teaching Hospital, Sagamu, Nigeria. Afr Health Sci. 2006; 6: 132-138. 